\title{
Granular cell tumors of the tracheobronchial tree
}

J. van der Maten, $M D^{\mathrm{a}}$

J. L. G. Blaauwgeers, $M D^{b}$

T. G. Sutedja, MD, $P D^{c}$

H. B. Kwa, MD, PhD

P. E. Postmus, MD, PhD

Sj. Sc. Wagenaar, MD, $P h D^{b}$
Objective: To describe the population-based incidence and clinical characteristics of granular cell tumors of the tracheobronchial tree.

Methods: All newly registered tracheobronchial granular cell tumors in the Dutch Network and National Database for Pathology for 10 consecutive years (1990-1999) were identified. The histologic diagnosis was confirmed and patient demographics, management, and follow-up data were analyzed.

Results: Thirty-one tumors were registered in 30 patients (12 male patients and 18 female patients; mean age 51 years; range 11-84) in a population of approximately 15 million. Tracheal tumors were identified in 11 patients and bronchial tumors in 19 patients (1 patient had 2 tumors). About half of the patients were asymptomatic. In the majority of the patients $(61 \%)$ the granular cell tumor was an incidental finding during workup for lung carcinoma. Tracheal granular cell tumors were more frequent in women, whereas bronchial granular cell tumors showed no sex predilection. In the lung these tumors occurred more often in the upper (10 tumors) than in the lower lobes ( 3 tumors). There was no preference for either side. Four patients with tracheal and 4 with bronchial granular cell tumors were treated with surgery and remain in complete remission. Four bronchial granular cell tumor patients were treated locally with neodymium/yttrium-aluminum-garnet laser or electrocautery and are in complete remission or have stable residual disease. In 3 patients no residual disease was found after biopsy. Of all granular cell tumor patients 17 received no treatment for a variety of reasons, but none of these patients died in the follow-up period because of the granular cell tumors.

Conclusion: Tracheobronchial granular cell tumor is a benign tumor with a good prognosis. In symptomatic patients surgical intervention is the first choice of treatment, but local treatment is a reasonable option and gives successful results. \footnotetext{
and Pathology, ${ }^{\text {b }}$ Onze Lieve Vrouwe Gasthuis (OLVG), Amsterdam, The Netherlands, and Department of Pulmonology, ${ }^{\mathrm{c}}$ Vrije Universiteit Medical Center, Amsterdam, The Netherlands.

Received for publication Aug 5, 2002; revisions requested Sept 24, 2002; revisions received Jan 28, 2003; accepted for publication March 13, 2003.

Address for reprints: J. van der Maten, Department of Pulmonary Diseases, Medisch Centrum Leeuwarden (MCL), PO Box 888, 8901 BR Leeuwarden, The Netherlands (Email: j.maten@znb.nl).

J Thorac Cardiovasc Surg 2003;126:740-3

Copyright () 2003 by The American Association for Thoracic Surgery

$0022-5223 / 2003 \$ 30.00+0$

doi:10.1016/S0022-5223(03)00601-9
}

From the Departments of Pulmonology

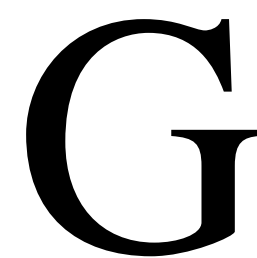

ranular cell tumors (GCTs) can occur in almost any organ. They are most frequent in the skin, tongue, and breast and have very rarely been reported in the digestive and respiratory tracts. They have also been reported to occur synchronously in multiple organs and metachronously in a single organ. The incidence of GCTs in the tracheobronchial tree is unknown. The aim of this study was to investigate the incidence of this rare tumor in The Netherlands, to assess its clinical presentation, and to evaluate the treatment results.

\section{Material and Methods}

A national survey was performed of all newly registered cases of GCTs in the Dutch Network and National Database for Pathology (PALGA) for 10 consecutive years (1990-1999). This database registers all pathologic diagnoses in The Netherlands, which includes a population of approximately 15 million people. Routine hematoxylin-eosin and available immunohisto- 
chemical slides were reviewed by two authors (Sj.Sc.W., J.L.G.B.) independently. Clinical data including age, gender, presenting symptoms, site, treatment, and outcome were analyzed. All data were treated according the National privacy legislation.

\section{Results}

\section{Histopathologic Features}

The histologic slides were reviewed and the diagnosis of GCT confirmed in all cases. The tumors varied in size: tracheal tumors measured 2 to $30 \mathrm{~mm}$ (mean 10.7) and bronchial tumors 2 to $35 \mathrm{~mm}$ (mean 5.6). Microscopically, the tumors had an indistinct border, with neoplastic cells infiltrating the surrounding tissue. The tumor cells were polygonal or ovoid, with abundant eosinophilic and granular cytoplasm. The nuclei were small, hyperchromatic, and sometimes eccentrically located. In submucosal tumors, the overlying epithelium showed squamous metaplasia without dysplasia (6 tracheal tumors and 5 bronchial tumors). The periodic acid-Schiff stain was positive and diastase resistant in all cases, which is evidence for the presence of glycogen. In 15 of the 31 cases the immunohistochemical S-100 protein stain was available and appeared to be positive in all cases. Although these tumors tend to infiltrate their immediate surroundings, on review of the slides, it was not possible to determine the maximal depth of infiltration. No signs of malignancy (atypia, mitotic figures, or vascular invasion) could be found.

\section{Clinical Features}

Thirty-one GCTs of the tracheobronchial tree were identified; all were confirmed by the reviewers and were histological benign (see below). Patient demographics and clinical data are shown in Table 1. Limited data were available for size (4 tracheal tumors), treatment (1 tracheal tumor), follow-up (1 tracheal tumor and 1 bronchial tumor), and smoking history ( 7 tracheal tumors and 2 bronchial tumors). Eleven tumors were tracheal and 20 were bronchial. Among the patients with tracheal GCTs, 3 were male patients (mean age 66 years; range 55-77) and 8 were female patients (mean age 33 years; range 11-45). Among those with bronchial GCTs, 9 were men (mean age 57 years; range 43-84) and 10 were women (mean age 49 years; range 37-67). For both bronchial and tracheal tumors, the mean age of the female patients was lower than the mean age of the male patients. In 1 male patient 2 GCTs were found. The majority of patients $(65 \%)$ were cigarette smokers.

The bronchial GCTs were equally distributed over both lungs and showed a preference for the upper lobes (Table 1). The patient with 2 bronchial GCTs had 1 tumor in the left upper lobe and 1 tumor in the intermediate bronchus.

Treatment and follow-up data of all patients are shown in Table 2. Of the 11 tracheal GCTs, 4 were completely resected and followed by tracheal reconstruction; tumors had a mean tumor diameter of $27 \mathrm{~mm}$ (range 25-30). In 2
TABLE 1. Demographic and clinical data

\begin{tabular}{lccc}
\hline n (patients) & $\begin{array}{c}\text { Overall } \\
\text { (n= 30) }\end{array}$ & $\begin{array}{c}\text { Tracheal } \\
(\mathbf{n}=\mathbf{1 1})\end{array}$ & $\begin{array}{c}\text { Bronchial } \\
\text { (n = 19) }\end{array}$ \\
\hline Mean age, years (range) & $48(11-84)$ & $42(11-77)$ & $52(37-84)$ \\
M/F & $12 / 18$ & $3 / 8$ & $9 / 10$ \\
Smoker Y/N (unknown) & $20 / 1(9)$ & $3 / 1(7)$ & $17 / 0(2)$ \\
Other neoplasms & 11 & $2^{*}$ & $9 \dagger$ \\
Follow-up months & $1-120$ & $1-120$ & $2-72$ \\
Localization GCT & & & 2 right, 2 left \\
$\quad$ Main bronchus & & & 3 \\
$\quad$ Intermediate bronchus & & & 4 right, 6 left \\
$\quad$ Upper lobes & & & 1 right, 2 left \\
$\quad$ Lower lobes & & & 3 \\
Symptoms & 6 & 3 & 0 \\
$\quad$ Cough & 2 & 2 & 3 \\
$\quad$ Stridor & 5 & 2 & 12 \\
$\quad$ Dyspnea & 16 & 4 & \\
$\quad$ None & & & \\
\hline
\end{tabular}

${ }^{*}$ NSCLC (1), malignant pleuritis secondary to ovarian carcinoma (1). †NSCLC (7), carcinoid (1), laryngeal carcinoma (1).

patients surgical intervention took place after neodymium/ yttrium-aluminum-garnet (Nd-Yag) laser treatment, and in 1 patient the GCT was removed after a previous incomplete endoscopic resection. In 6 tracheal tumors, no treatment was performed after diagnostic endoscopy. In the remaining case the treatment modality is unknown, as well as the follow-up. The 4 patients with tracheal GCTs treated surgically became tumor-free (mean 68 months, range 3-120). Three of the patients with tracheal GCTs died of unrelated causes. Two patients were alive after 4 years of follow-up, with stable disease and complete remission proven by bronchoscopy. One patient was alive after 30 months but was then lost to follow-up.

Of the bronchial group, 4 patients with GCTs in the main bronchi received endobronchial therapy (electrosurgery or Nd-Yag laser) and 4 patients underwent surgery (left pneumonectomy in 1 , right lower lobe resection in 1 , and right upper lobe resection in 2 patients). The indications for left pneumonectomy and right lower lobe resection were primarily the presence of a non-small cell lung cancer and not the GCT. In 3 patients no residual tumor was present after diagnostic endobronchial biopsy.

Ten of the 19 patients for whom clinical data were available and who had a bronchial localization of the GCT remained in complete remission, whereas 4 patients continued to live with stable disease (Table 2).

\section{Discussion}

This retrospective search over 10 consecutive years from a population of approximately 15 million yielded 31 cases of GCTs in 30 patients (population-based incidence $2: 100,000)$. GCTs are well-known tumors particularly in the breast, tongue, and skin but may occur in any organ. ${ }^{1}$ It is 
TABLE 2. Treatment and follow-up

\begin{tabular}{|c|c|c|c|}
\hline Location & Treatment & n (patients) & Follow-up (period in months) \\
\hline \multirow[t]{3}{*}{ Trachea } & Surgery & 4 & In 4 , no recurrent disease $(3-120)$ \\
\hline & None & 7 & In 3 , no tumor-related deaths (1-12) \\
\hline & & & 3 still alive $(30-90)$ and in 1 , no data available \\
\hline \multirow[t]{7}{*}{ Bronchus } & Surgery & 4 (1 pneumonectomy, and 3 lobectomy) & In 4 , no recurrent disease (4-72) \\
\hline & Electrocautery & 2 & In 2, no recurrent disease $(9-60)$ \\
\hline & Nd-YAG laser & 2 & $\begin{array}{l}\text { In 1, complete remission (12) } \\
\text { In 1, stable disease (6) }\end{array}$ \\
\hline & None & 11 & In 4, no tumor-related death (4-24) \\
\hline & & & In 3 , no tumor after biopsy (1-72) \\
\hline & & & In 3 , stable disease $(2-24)$ \\
\hline & & & One patient lost to follow-up (12) \\
\hline
\end{tabular}

now generally believed that these tumors are of Schwann cell origin. Therefore, S-100 protein is usually expressed by the cells as shown in all of our cases where staining was performed. The growth rate is low. In nontracheobronchial tumors recurrent disease may occur after many years. The biopsy-proven stable disease in patients of our study suggests that pulmonary tumors are likely to have the same biologic behavior as tumors in other organs. There is little data about inducing factors. In our series $65 \%$ of the patients were smokers (smoking history was unknown in 9 patients). Because of the small number of patients and the missing data, however, speculation about whether GCT is a smoking-related disease would not be adequate. In this series of tracheobronchial GCTs no malignant tumors were found. A malignant variant in the lung has never been published. Multicentric tumors, however, have been described, ${ }^{2}$ but in contrast to what is mentioned by Valenstein and Thurer, ${ }^{3}$ no multicentric tracheal tumors were found. In our series only 1 patient had 2 primary lung GCTs (3\%), much less than the $25 \%$ published by Deavers and colleagues. ${ }^{4}$ Although no clinical data were available concerning extrapulmonary GCTs in this study, in 1 case a second primary GCT in the esophagus was found. The esophagus is, besides the tongue, not an unusual second organ to be involved. ${ }^{1,5}$ In accordance with other studies ${ }^{6}$ the incidence of tracheal GCTs is lower in comparison with bronchial tumors, but higher in adults and in women. The last finding is in analogy to what has been reported for esophageal tumors. ${ }^{7}$ However, in these series bronchial GCTs are equally represented in both sexes.

In our series these tumors had a preference for the upper lobes and the intermediate bronchus, although this finding has not been confirmed by others. ${ }^{4}$ Other lung tumors, in particular lung cancers, have a similar tendency. In 11 of 18 of our patients the GCT was an incidental finding identified during workup for a malignancy. Eight patients had lung cancer, 1 had a bronchial carcinoid, 1 had a malignant pleural effusion (secondary to ovarian cancer), and 1 had a laryngeal carcinoma. This last coincidence is also described by Cutlan and Eltorky. ${ }^{8}$ Our findings are in accordance with the study of Deavers and colleagues, ${ }^{4}$ in which GCTs were an incidental finding radiographically or bronchoscopically in one half of the patients.

Centrally located tumors are more likely to cause symptoms due to their mechanical characteristics and make treatment necessary. However, Daniel and colleagues ${ }^{6}$ reported that tumors with a diameter of $8 \mathrm{~mm}$ or greater are likely to invade the full-thickness bronchial wall, with infiltration into the peribronchial tissue. The treatment modality of choice for a tracheal tumor is dependent on the invasion of the tracheal wall and should be evaluated by high-resolution computed tomography or magnetic resonance imaging. ${ }^{9,10}$ Therefore, we believe that, except in cases that need a surgical intervention (on the basis of their size or symptoms), primary GCTs are suitable for endobronchial therapy. ${ }^{9,10}$ The slow growth rate of GCTs makes follow-up of once a year for at least 5 years to detect recurrences necessary. In our series no retreatment was indicated, and the majority of the patients were in complete remission after 1 treatment. Patients treated with surgery remained in remission for up to 10 years. Even patients with residual disease continued to live with stable disease, suggesting a very benign course. Therefore, treatment is probably only necessary in patients with local symptoms and, if possible, local treatment is preferred.

We thank all the contributing hospitals for their data and PALGA foundation (Utrecht, The Netherlands) for the use of the database. The authors would also like to thank H. D. Tazelaar, MD (Mayo Clinic, Rochester, Minn), for his critical remarks.

\section{References}

1. Ordonez NG. Granular cell tumor: a review and update. Adv Anat Pathol. 1999;6:186-203.

2. Ostermiller WE, Comer TF, Vakil HC. Endobronchial granular cell myoblastoma. A report of three cases and review of the literature. Ann Thorac Surg. 1970;9:143-8.

3. Valenstein SL, Thurer RJ. Granular cell myoblastoma of the bronchus. J Thorac Cardiovasc Surg. 1978;76:465-8.

4. Deavers M, Guinee D, Koss MN, Travis WD. Granular cell tumors of the lung. A clinicopathologic study. Am J Surg Pathol. 1995;19:62735 . 
5. Oparah SS, Subramanian VA. Granular cell myoblastoma of the bronchus: report of 2 cases and review of the literature. Ann Thorac Surg. 1976;22:199-202.

6. Daniel TM, Smith RH, Faunce HF, Sylvest VM. Transbronchoscopic versus surgical resection of the tracheobronchial granular cell myoblastoma. Suggested approach based on follow-up of all treated cases. J Thorac Cardiovasc Surg. 1980;8:898-903.

7. Voskuil JH, Dijk van MM, Wagenaar SjSc, Vliet van ACM, Timmer $\mathrm{R}$, Hees van PAM. Occurrence of esophageal granular cell tumors in the Netherlands between 1988 and 1994. Dig Dis Sci. 2001;46:1610-4.

8. Cutlan RT, Eltorky M. Pulmonary granular cell tumor coexisting with bronchogenic carcinoma. Ann Diagn Pathol. 2001;5:74-9.

9. Sutedja G, Schramel F, Postmus PE. Bronchoscopic treatment modalities in lung cancer, indications and limitations. Chest. 1995;107: 556-8.

10. Lee P, Kupeli E, Mehta AC. Therapeutic bronchoscopy in lung cancer. Laser therapy, electrocautery, brachytherapy, stents and photodynamic therapy. Clin Chest Med. 2002;23:241-56.

\section{Availability of Journal back issues}

As a service to our subscribers, copies of back issues of The Journal of Thoracic and Cardiovascular Surgery for the preceding 5 years are maintained and are available for purchase from Mosby until inventory is depleted. Please write to Mosby, Subscription Customer Service, 6277 Sea Harbor Dr, Orlando, FL 32877, or call $800-654-2452$ or $407-345-4000$ for information on availability of particular issues and prices. 